\title{
Environmental effects on mechanical, thermophysical and electrical properties of epoxy resin filled with carbon nanofillers
}

Cite as: AIP Conference Proceedings 2196, 020004 (2019); https://doi.org/10.1063/1.5140277 Published Online: 12 December 2019

T. Glaskova-Kuzmina, A. Aniskevich, J. Sevcenko, A. Zotti, A. Borriello, and M. Zarrelli

\section{ARTICLES YOU MAY BE INTERESTED IN}

Preface: The 9th International Conference on Structural Analysis of Advanced Materials (ICSAAM 2019)

AIP Conference Proceedings 2196, 010001 (2019); https://doi.org/10.1063/1.5140273

Polyaniline based composite layers for photovoltaïc applications: Thermal and optical properties investigation

AIP Conference Proceedings 2196, 020002 (2019); https://doi.org/10.1063/1.5140275

Advances in polymer composites' tribology

AIP Conference Proceedings 2196, 020001 (2019); https://doi.org/10.1063/1.5140274
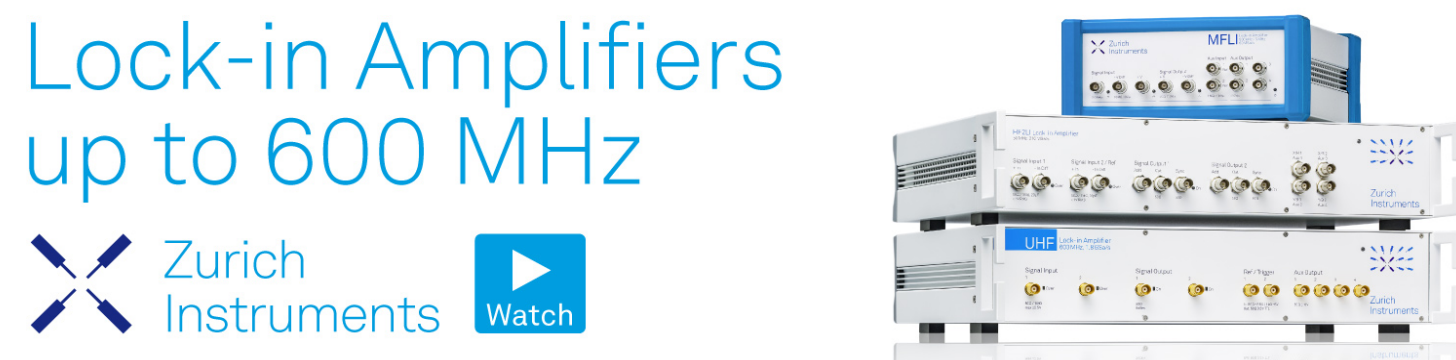


\title{
Environmental Effects on Mechanical, Thermophysical and Electrical Properties of Epoxy Resin Filled with Carbon Nanofillers
}

\author{
T. Glaskova-Kuzmina ${ }^{1, \text { a) }}$, A. Aniskevich ${ }^{1, b)}$, J. Sevcenko ${ }^{1, \mathrm{c})}$, A. Zotti $^{2, \mathrm{~d}}$, \\ A. Borriello ${ }^{2, \text { e) }}$, and M. Zarrelli ${ }^{2, \text { f) }}$ \\ ${ }^{1}$ Institute for Mechanics of Materials, University of Latvia, Riga, Latvia. \\ ${ }^{2}$ Institute for Polymers, Composites and Biomaterials, National Research Council of Italy, Portici, Italy. \\ a) Corresponding author: Tatjana.Glaskova-Kuzmina@lu.1v, \\ b) andrey.aniskevich@pmi.lu.lv, \\ c)evgs@inbox.lv, \\ d) aldobenedetto.zotti@unina.it, \\ e) anna.borriello@cnr.it, \\ f) mauro.zarrelli@cnr.it.
}

\begin{abstract}
The aim of this work was to establish the effect of environmental factors (moisture and temperature) on some mechanical, electrical and thermal properties of epoxy-based composites filled with carbon nanofillers: nanotubes (CNT), nanofibers (CNF) and hybrid nanofiller (nanotubes/nanofibers in the ratio 1:1) and to reveal the most environmentally stable NC. First, the nanocomposites (NC) containing different nanofiller contents were prepared to evaluate electrical percolation threshold and to choose $\mathrm{NC}$ at certain electrical conductivity for further characterization of the physical properties in initial state and during/after environmental ageing. The environmental ageing consisted of water absorption at $70{ }^{\circ} \mathrm{C}$ until equilibrium moisture content reached all samples in 4 weeks and 2) heating at $70{ }^{\circ} \mathrm{C}$ for the same time, and 3) freezing at $-20{ }^{\circ} \mathrm{C}$ for 8 weeks. Two concurrent factors, temperature and moisture, led to post-curing of all materials studied without significant plastization. Some positive nanofiller effects were found for sorption, mechanical and thermophysical characteristics of RTM6 epoxy resin. Based on experimental results, the most environmentally stable NC was epoxy filled with 0.1 wt. \% of CNT/CNF hybrid, which had the lowest effect of temperature and moisture on thermal and electrical conductivities, along with the lowest equilibrium water content and diffusivity.
\end{abstract}

\section{INTRODUCTION}

The interest of using carbon nanofillers arises due to unique combination of their mechanical, thermal and electrical properties, which may allow significant weight savings for the products in comparison with micro-filled composites and add multifunctionality to previously non-conductive polymer resins. However, usually such materials are mostly limited to indoor applications due to sensitivity of their physical properties to environmental factors, such as moisture and temperature [1]. The consideration of environmental effects and the reveal of the most environmentally stable electropassive nanocomposite $(\mathrm{NC})$ can broaden their application to outdoor conditions.

The aim of this work was to establish the effect of environmental factors (moisture and temperature) on the main mechanical, electrical and thermal properties of epoxy-based composites filled with carbon nanofillers: nanotubes, 
nanofibers and hybrid nanofiller (nanotubes/nanofibers in the ratio 1:1) for the use as electropassive damage-indicating material in structural outdoor applications and to reveal the most environmentally stable NC.

\section{EXPERIMENTAL}

\section{Investigated Materials}

A commercially available monocomponent RTM6 (Hexcel Composites) epoxy resin was used as a matrix material. Two different carbon nanofillers were chosen: 1) multiwall carbon nanotubes (CNT) Nanocyl 7000 (Nanocyl, Belgium), 2) carbon nanofibres (CNF) SA 719781 (Sigma-Aldrich, USA). Additionally, a hybrid nanofiller (HN) loading, consisting of both CNT and CNF in the ratio 1:1 by weight was prepared.

First, different nanofiller contents were chosen in order to evaluate electrical percolation threshold of the NC: 1) for RTM6 filled with CNT - 0.01, 0.02, 0.03, 0.05 and $0.1 \mathrm{wt}$ \%; 2) for RTM6 filled with CNF - 0.1, 0.2, 0.3, 0.4 and 0.5 wt. \%; 3 ) for RTM6 filled with $\mathrm{HN}-0.02,0.04,0.06,0.1$ and $0.2 \mathrm{wt} . \%$. Then, the samples of neat epoxy and $\mathrm{NC}$ at certain electrical conductivity $(\sigma \approx 0.1-0.01 \mathrm{~S} / \mathrm{m})$ were prepared for the characterization of mechanical, thermophysical and electrical properties in initial state and during/after environmental ageing. Thus, the epoxy was filled with 0.05 wt. $\%$ of CNT, 0.3 wt. $\%$ of CNF and 0.1 wt. $\%$ of CNT/CNF.

\section{Methods}

The dispersion of all nanofillers within the epoxy matrix was performed by high-shear disperser Ultra Turrax T25 combined with a heating plate RCT basic (IKA, Germany) for $30 \mathrm{~min}$ at $90^{\circ} \mathrm{C}, 20 \mathrm{krpm}$. Then, the mixtures were degassed at $90{ }^{\circ} \mathrm{C}$ to remove the air bubbles and ultimately cured for $90 \mathrm{~min}$ at $160^{\circ} \mathrm{C}$ with a subsequent post cure cycle for $2 \mathrm{~h}$ at $180^{\circ} \mathrm{C}$. The environmental ageing consisted of 1 ) water absorption at $70^{\circ} \mathrm{C}$ until equilibrium moisture content was reached by all samples in 4 weeks, 2) heating at $70^{\circ} \mathrm{C}$ for 4 weeks, and 3) freezing at $-20^{\circ} \mathrm{C}$ for 8 weeks.

The mechanical properties for epoxy and NC samples were tested under three-point bending mode according to ASTM D790. The samples of sizes $3 \times 10 \times 80 \mathrm{~mm}$ were tested with a support span of $56 \mathrm{~mm}$ and with a strain rate of $1.5 \mathrm{~mm} / \mathrm{min}$. The flexural modulus, strength and maximal deformation were evaluated from the stress-strain curves. The electrical resistance of the NC samples was measured by using a multimeter DMM 4020 (Tektronix, USA) following a two-point methodology. Opposite facets of the samples were covered with conductive silver paint to reduce contact resistance effect. The thermal conductivity was measured by using thermal constants analyzer TPS 500 (Hot Disc, Sweden) at a heating power $50 \mathrm{~mW}$ and heating time $40 \mathrm{~s}$ by using Kapton sensor with radius $3.2 \mathrm{~mm}$. The dynamic mechanical thermal analysis (DMTA) was carried out by using a Mettler Toledo (USA) DMA/SDTA861 in tensile mode at a given force $4 \mathrm{~N}$, frequency $10 \mathrm{~Hz}$ and $\mathrm{T}=30-280^{\circ} \mathrm{C}$ at $3 \mathrm{~K} / \mathrm{min}$ heating rate to evaluate hygrothermal ageing effects in both initial and environmentally "aged" $\mathrm{NC}$ samples.

\section{RESULTS}

\section{Water Absorption}

The peculiarities of moisture absorption in epoxy resin and NC samples were studied. The overall behavior was similar for all materials (see Fig. 1a) following classical Fick's law for 1D moisture diffusion (when thickness $a$ of the specimen is significantly smaller than its width)

$$
w(t)=w_{\infty}-\left(w_{\infty}-w_{0}\right) \frac{2}{\pi^{2}} \sum_{k=1}^{\infty} \frac{\left(1-(-1)^{k}\right)^{2}}{k^{2}} \exp \left(-\left(\frac{\pi k}{a}\right)^{2} D t\right),
$$

where $w(t), w_{0}$ and $w_{\infty}$ are time-varying, initial and the equilibrium moisture contents of a specimen, and $D$ is the diffusion coefficient of the material, respectively. The equilibrium moisture content is evaluated as maximally achieved moisture content over the sorption test, while the diffusion coefficient is calculated from the initial slope of the curve $w$ vs. $\sqrt{t} \quad$ [2]: 


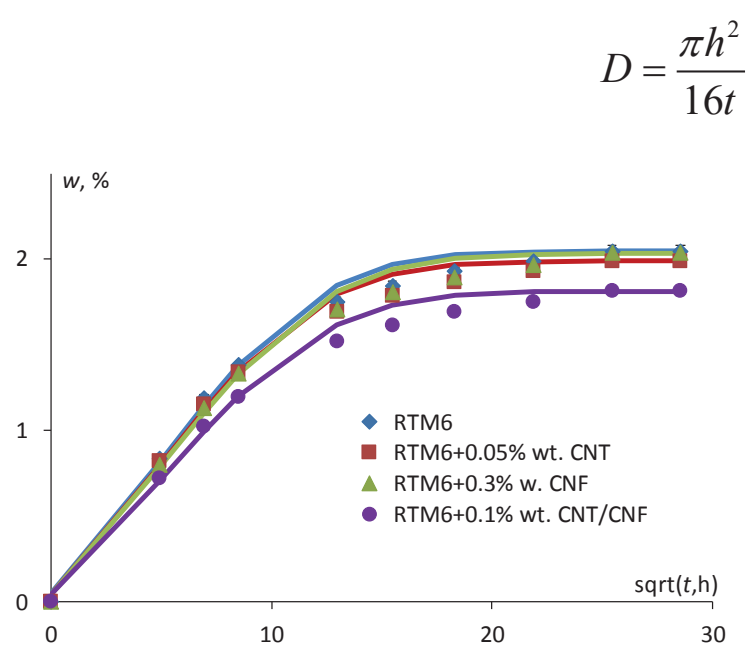

(a)

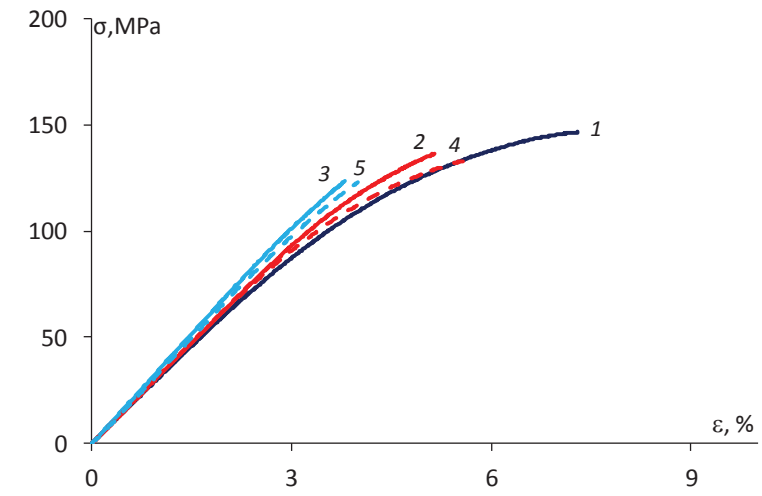

(b)

FIGURE 1. Moisture absorption kinetics of epoxy and epoxy filled with CNT and/or CNF as indicated in the legend (a). Dots experimental data, lines - evaluation by Eq. (1). Representative stress-strain curves for the epoxy in uncondensed state (1) and after heating (2), water absorption (3), heating and freezing (4), water absorption and freezing (5) (b).

According to Fig. 1 the addition of stiff moisture impenetrable carbon nanofillers caused a slight reduction of equilibrium moisture content: $2.05 \%$ for epoxy resin, and $2.04 \%, 1.99 \%$, and $1.81 \%$ for epoxy filled with 0.3 wt. $\%$ of CNF, 0.05 wt. \% of CNT and $0.1 \mathrm{wt} . \%$ of HN, accordingly. The diffusivity of the NC was almost the same as for the neat epoxy resin: $1.58 \pm 0.0610^{4} \times \mathrm{cm}^{2} / \mathrm{h}$ for epoxy resin, $1.56 \pm 0.0610^{4} \times \mathrm{cm}^{2} / \mathrm{h}$ for epoxy filled $0.05 \mathrm{wt} . \%$ of CNT, $1.63 \pm 0.0810^{4} \times \mathrm{cm}^{2} / \mathrm{h}$ for epoxy filled with $0.3 \mathrm{wt}$. \% of CNF and $1.56 \pm 0.0810^{4} \times \mathrm{cm}^{2} / \mathrm{h}$ for epoxy filled with 0.1 wt. $\%$ of $\mathrm{CNT} / \mathrm{CNF}$.

\section{Flexural, Thermophysical and Electrical Properties}

\section{Flexural properties}

The representative stress-strain curves for the epoxy are shown in Fig. 1b. For the NC the overall behavior of the curves was similar as for the epoxy. Thus, in uncondensed state, before environmental ageing, the flexural properties were almost the same for all materials studied: flexural modulus was $2.9 \pm 0.1 \mathrm{GPa}$, strength was $140 \pm 5 \mathrm{MPa}$, maximal deformation was $6.5 \pm 0.5 \%$. According to Fig. $1 \mathrm{~b}$ after the first stage of environmental ageing, which lasted 4 weeks and consisted of two parallel processes, heating at $70{ }^{\circ} \mathrm{C} \mathrm{(2)} \mathrm{and} \mathrm{water} \mathrm{absorption} \mathrm{at} 70{ }^{\circ} \mathrm{C}(3)$, an increase in flexural modulus was observed for all materials studied. The flexural modulus of the epoxy and the NC was increased by app. $3.5-4.0 \%$ after the heating, and by $6.5-8.1 \%$ after the moisture absorption. Then, after the second stage of environmental ageing, freezing after water absorption (4) and freezing after heating (5) the flexural modulus was slightly reduced in comparison with the values after water absorption and heating: by $3-4 \%$ for epoxy, and by $1-3 \%$ for all NC. As seen from Fig. 1b, due to environmental ageing (water absorption, heating and then freezing) the strength of epoxy was decreased by app. $7 \%(1-4)$ and by $5 \%(1-5)$, while the maximal deformation was reduced by app. 30$35 \%$ for the epoxy and by $20-25 \%$ for the NC both due to water absorption and heating.

\section{Thermophysical properties}

The thermal conductivity of the epoxy and the $\mathrm{NC}$ in uncondensed state was almost the same $(0.23 \pm 0.02 \mathrm{~J} / \mathrm{mK})$. According to Fig. 2a the first stage of environmental ageing caused an increase of thermal conductivity for all materials: after heating (by 2.6-10.1\%) and after water absorption (by $0.5-15 \%)$. The lowest effect $+0.5 \%(1-3)$ and $+2.6 \%(1-2)$ was observed for epoxy filled with $0.1 \%$ of HN. After freezing, the thermal conductivity of the epoxy and the NC was reduced by app. $2.5-5.5 \%$ and by app. $1.4-9.6 \%$ for dry and moistened materials, accordingly. The glass transition temperature for epoxy and epoxy filled with all carbon nanofillers obtained from DMTA was almost the same in initial state and after heating and water absorption $\left(235 \pm 3{ }^{\circ} \mathrm{C}\right)$ and can be attributed to several contrary 
acting factors such as existence of interphases/interfaces on the surface of the nanoparticles, agglomerates, changes in crystallinity and cross-link density of the epoxy resin [3].

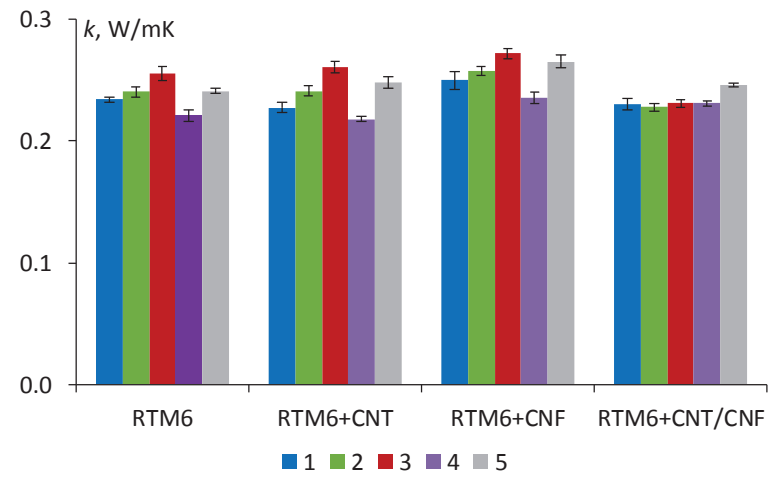

(a)

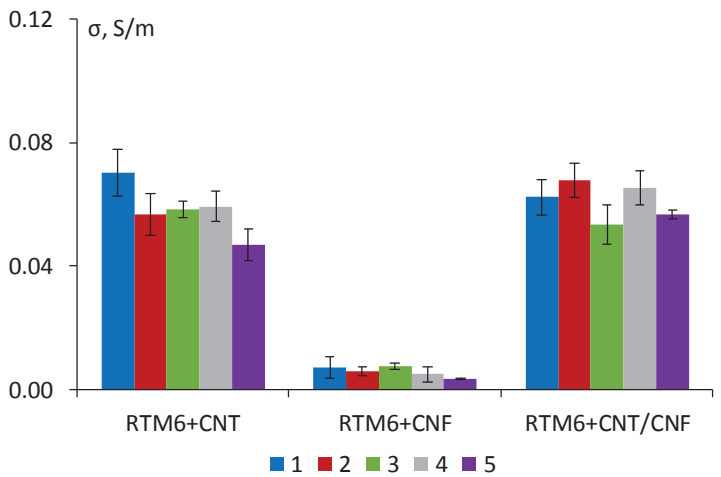

(b)

FIGURE 2. Thermal conductivity (a) and electrical conductivity (b) in uncondensed state (1) and after heating (2), water absorption (3), heating and freezing (4), water absorption and freezing (5).

\section{Electrical Properties}

According to Fig. $2 \mathrm{~b}$ the electrical conductivity in uncondensed state, of the epoxy filled with $0.05 \mathrm{wt}$ \% of CNT was $0.070 \pm 0.008 \mathrm{~S} / \mathrm{m}$, for the epoxy filled with $0.3 \mathrm{wt} . \%$ of CNF $-0.007 \pm 0.003 \mathrm{~S} / \mathrm{m}$, and for the epoxy filled with 0.1 wt. \% of $\mathrm{HN}-0.062 \pm 0.006 \mathrm{~S} / \mathrm{m}$. Both temperature and moisture affected the electrical conductivity for all NC samples. In 4 weeks of heating and water absorption it decreased by $16 \%$ (2) and 19\% (3) for CNT-filled, by $9 \%$ (2) and 19\% (3) for CNF-filled, and by $8 \%(2)$ and $18 \%$ (3) for HN-filled epoxy resin, accordingly. In 8 weeks of freezing the electrical conductivity was reduced by $15.5 \%$ (1-4) and $33.3 \%$ (1-5) for CNT-filled, by $30.2 \%(1-4)$ and $49.8 \%$ (1-5) for CNF-filled, and by $4.9 \%(1-4)$ and $8.8 \%$ (1-5) for HN-filled epoxy, accordingly. Thus, the HN showed the highest stability of the electrical conductivity to the environmental ageing.

\section{CONCLUSIONS}

Two concurrent factors, temperature and moisture, led to post-curing of all materials studied without significant plastization. The addition of carbon nanofillers has resulted in slight positive effect for sorption, mechanical and thermophysical characteristics of the epoxy resin. Based on experimental results the most environmentally stable NC was epoxy filled with $0.1 \mathrm{wt}$. \% of HN, which had the lowest effect of temperature and moisture on flexural modulus and strength, thermal and electrical conductivities, along with the lowest equilibrium water content and diffusivity.

\section{ACKNOWLEDGEMENTS}

This work was financially supported by ERDF project No. 1.1.1.2/VIAA/1/16/066 for the support of post-doctoral research "Environmental effects on physical properties of smart composites and fibre-reinforced plastics modified by carbonaceous nanofillers for structural applications".

\section{REFERENCES}

1. T. Glaskova-Kuzmina, A. Aniskevich, A. Martone, M. Giordano, M. Zarrelli, "Effect of moisture on elastic and viscoelastic properties of epoxy and epoxy-based carbon fibre reinforced plastic filled with multiwall carbon nanotubes", Composites: Part A 90, 522-527 (2016).

2. A.C. Loos, G.S. Springer. Environmental effects on composite materials. Westport: Technomic Publishing Co 1981.

3. O. Starkova, S.T. Buschhorn, E. Mannov, K. Schulte, A. Aniskevich. "Water transport in epoxy/MWCNT composites", European Polymer Journal 49, 2138-2148 (2013). 